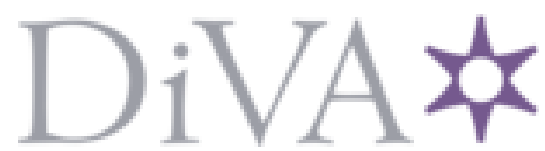

http://www.diva-portal.org

This is the published version of a paper published in Chemistry - A European Journal.

Citation for the original published paper (version of record):

Nagendiran, A., Pascanu, V., Bermejo Gómez, A., González Miera, G., Tai, C-W. et al. (2016)

Mild and Selective Catalytic Hydrogenation of the $\mathrm{C}=\mathrm{C}$ Bond in a,b-Unsaturated Carbonyl

Compounds Using Supported Palladium Nanoparticles.

Chemistry - A European Journal, 22(21): 7184-7189

https://doi.org/10.1002/chem.201600878

Access to the published version may require subscription.

N.B. When citing this work, cite the original published paper.

Reprinted with permission of Chemistry - A European Journal, 2016, 22 (21) 7184-7189. Copyright 2016 John Wiley and sons.

Permanent link to this version:

http://urn.kb.se/resolve?urn=urn:nbn:se:su:diva-132708 


\title{
Heterogeneous Catalysis
}

\section{Mild and Selective Catalytic Hydrogenation of the $\mathrm{C}=\mathrm{C}$ Bond in $\alpha, \beta$-Unsaturated Carbonyl Compounds Using Supported Palladium Nanoparticles}

\author{
Anuja Nagendiran ${ }^{+}{ }^{[a]}$ Vlad Pascanu ${ }^{+}{ }_{1}^{\text {a] }}$ Antonio Bermejo Gómez, ${ }^{[a, c]}$ Greco González Miera, ${ }^{\text {[a] }}$ \\ Cheuk-Wai Tai, ${ }^{[b]}$ Oscar Verho, ${ }^{*[a]}$ Belén Martín-Matute, ${ }^{*[a]}$ and Jan-E. Bäckvall*[a]
}

\begin{abstract}
Chemoselective reduction of the $\mathrm{C}=\mathrm{C}$ bond in a variety of $\alpha, \beta$-unsaturated carbonyl compounds using supported palladium nanoparticles is reported. Three different heterogeneous catalysts were compared using 1 atm of $\mathrm{H}_{2}$ : 1) nano-Pd on a metal-organic framework (MOF: $\mathrm{Pd}^{0}-\mathrm{MIL}-$ 101- $\left.\mathrm{NH}_{2}(\mathrm{Cr})\right)$, 2) nano-Pd on a siliceous mesocellular foam (MCF: $\mathrm{Pd}^{0}$-AmP-MCF), and 3) commercially available palladium on carbon $(P d / C)$. Initial studies showed that the
\end{abstract}

Pd@MOF and Pd@MCF nanocatalysts were superior in activity and selectivity compared to commercial $\mathrm{Pd} / \mathrm{C}$. Both $\mathrm{Pd}^{0}$ MIL-101- $\mathrm{NH}_{2}(\mathrm{Cr})$ and $\mathrm{Pd}^{0}$-AmP-MCF were capable of delivering the desired products in very short reaction times (10$90 \mathrm{~min})$ with low loadings of $\mathrm{Pd}(0.5-1 \mathrm{~mol} \%)$. Additionally, the two catalytic systems exhibited high recyclability and very low levels of metal leaching.

\section{Introduction}

Catalytic hydrogenation reactions have proven to be highly important transformations in organic synthesis. In 2013, one fourth of all drugs, marketed or in clinical trials, involved at least one hydrogenation step in their synthetic route. ${ }^{[1]}$ The chemoselective hydrogenation of olefinic bonds in the presence of other reducible functional groups such as aldehydes or ketones is an important but particularly challenging transformation. Most catalysts, especially heterogeneous ones, are severely limited in terms of selectivity and their applicability is restricted to non-challenging substrates. ${ }^{[2]}$

Metal-organic frameworks (MOFs) ${ }^{[3]}$ are crystalline porous materials with very high surface areas and tunable pore sizes from micro- to mesopores, that have been successfully applied

[a] Dr. A. Nagendiran, ${ }^{+}$V. Pascanu, ${ }^{+}$Dr. A. Bermejo Gómez, G. González Miera, Dr. O. Verho, Prof. Dr. B. Martín-Matute, Prof. Dr. J.-E. Bäckvall

Department of Organic Chemistry and

Berzelii Centre EXSELENT on Porous Materials

Arrhenius Laboratory, Stockholm University

10691 Stockholm (Sweden)

E-mail: Oscar@organ.su.se

belen.martin.matute@su.se

jan.e.backvall@su.se

[b] Dr. C.-W. Tai

Department of Materials and Environmental Chemistry

Stockholm University, 10691 Stockholm (Sweden)

[c] Dr. A. Bermejo Gómez

Current address:

AstraZeneca Translational Science Center at Karolinska Institute

17165 Stockholm (Sweden)

$\left.{ }^{+}\right]$These authors contributed equally to this work.

$\square$ Supporting information for this article can be found under http:// dx.doi.org/10.1002/chem.201600878. as supports in heterogeneous catalysis. ${ }^{[4]}$ On the other hand, porous siliceous materials such as mesocellular foams (MCFs), although amorphous, consist of an adjustable three-dimensional network of pores and display a significantly broader range of pore sizes of up to $50 \mathrm{~nm}$. Therefore they can promote a more efficient mass transfer. The siliceous MCF that has been the subject of work in our group ${ }^{[5]}$ delivers a high surface concentration of silanol groups that can be further functionalized. In a similar way, the inner surface of MOFs' pores can be tailored by anchoring functional groups onto the organic linkers, either directly in the synthesis process or through postsynthetic modification techniques. Both $\mathrm{MOFs}^{[6]}$ and $\mathrm{MCFs}^{[7]}$ have been successfully used to support metallic nanocatalysts. The confined environment created around the catalyst can lead to a different reactivity than that observed in solution. Often, this reactivity is also dependent on the size and shape of the nanoparticles. ${ }^{[8]}$ Furthermore, the porous nature of the supports prevents aggregation of the metal. Finely dispersed nanoparticles with narrow size distributions can easily be obtained and protected in the absence of additional surfactants and their surface-dependent catalytic properties can be preserved.

In this study we have evaluated and compared the efficiency of palladium nanoparticles supported on siliceous mesocellular foam ( $\left.\mathrm{Pd}^{0}-\mathrm{AmP}-\mathrm{MCF}, 8 \mathrm{wt} \% \mathrm{Pd}\right)^{[9]}$ and on a metal-organic framework $\left(\mathrm{Pd}^{0}-\mathrm{MIL}-101-\mathrm{NH}_{2}(\mathrm{Cr}), 8 \mathrm{wt} \% \mathrm{Pd}\right)^{[4 \mathrm{~b}, 10]}$ with that of $\mathrm{Pd} / \mathrm{C}$. Both porous matrices have been pre-functionalized with pendant $-\mathrm{NH}_{2}$ groups, in order to stabilize the nanoparticles and to minimize Pd leaching upon repeated uses. Herein, we demonstrate the efficiency of the two porous nanocatalysts in the chemoselective reduction of the olefinic double bond of different $\alpha, \beta$-unsaturated carbonyl compounds. 


\section{Results and Discussion}

The hydrogenation of cinnamaldehyde ( 1 a) was chosen as the model reaction. The possible pathways the reaction can take are illustrated in Scheme 1. Under ideal conditions, the only operating pathway would be the selective reduction of the $\mathrm{C}=\mathrm{C}$ double bond (Pathway $\mathrm{A}$ ), leading to exclusive formation of 3-phenylpropanal (2a). Over-reduction to 3-phenylpropan-1ol ( $3 \mathrm{a}$; pathways $C$ and $C^{\prime}$ ) is favored by longer reaction times and/or harsher reaction conditions, such as higher temperature and increased $\mathrm{H}_{2}$ pressure. Additionally, the selectivity can be affected by other factors such as the type and morphology of the support, metal dispersion, steric constraints and electronic effects. Literature reports based on Ru and Pt nanoparticles demonstrated that the size of the nanoparticles does play an important role on the selectivity and that larger nanoparticles and aggregates are able to promote selective formation of the allylic alcohol $\mathbf{4} \mathbf{a}^{[11]}$ On these grounds we hypothesized that small, finely dispersed nanoparticles supported on porous MOFs and MCFs would have the right shape, size and environment to favor Pathway A over B and C.

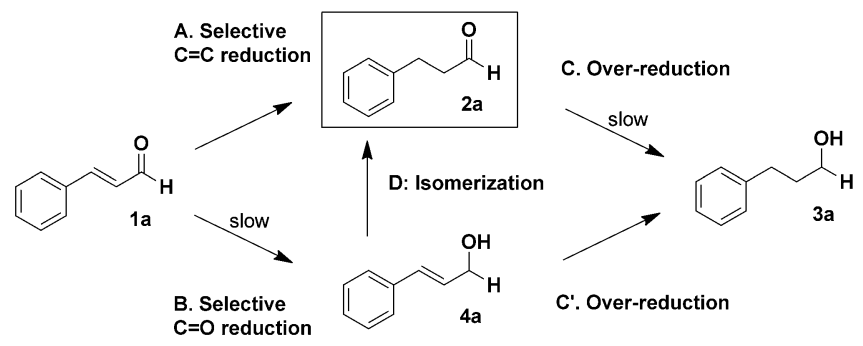

Scheme 1. Possible reaction pathways in the hydrogenation of cinnamaldehyde.

We set out to find the ideal conditions for a selective transformation by evaluating the behavior of the two catalysts $\left(\mathrm{Pd}^{0}\right.$ AmP-MCF and Pd ${ }^{0}-\mathrm{MIL}-101-\mathrm{NH}_{2}(\mathrm{Cr})$ ) together with that of $\mathrm{Pd} / \mathrm{C}$ in different solvents. As shown in Table 1, the efficiency of $\mathrm{Pd}^{0}$ MIL-101- $\mathrm{NH}_{2}(\mathrm{Cr})$ was mostly unaffected by the choice of solvent. Overall, excellent conversions (>99\%) and relatively high selectivities (89-90\%) were obtained within $90 \mathrm{~min}$ in all of the solvents examined (Table 1, entries 3-5). Shorter reaction times afforded lower conversions (Table 1, entries 1 and 2). On the contrary, the catalytic performances of $\mathrm{Pd}^{0}$-AmP-MCF (Table 1, entries 6-9) and of $\mathrm{Pd} / \mathrm{C}$ (Table 1, entries 10-13) were dependent on the solvent to a large extent. With $\mathrm{Pd}^{0}-\mathrm{AmP}-\mathrm{MCF}$, high conversions were obtained in both acetone and EtOAC (88 and $96 \%$, respectively) in only $30 \mathrm{~min}$; however, the selectivity towards the desired 3-phenylpropanal (2a) was higher in the latter solvent (86 vs. 94\%; Table 1, entries 6 and 7). ${ }^{[12]}$ Interestingly, although full conversion was achieved when the reaction time was prolonged to $60 \mathrm{~min}$ in EtOAc, a minor increase in over-reduction of $2 \mathrm{a}$ to 3 a could be observed ( $6 \%$ vs $8 \%$; Table 1, entry 7 vs. 8). Running the reaction in toluene resulted in lower conversion (66\%) and the selectivity decreased to $87 \%$ (Table 1, entry 9). For the commercially available Pd/C cat- alyst, the reaction had in general very poor selectivities (50$73 \%)$ and low conversions (36-68\%) in all the tested solvents (Table 1, entries 10-13). The reactions catalyzed by $\mathrm{Pd} / \mathrm{C}$ were generally slower than those catalyzed by the other two nanopalladium catalysts, and among them $\mathrm{Pd}^{0}$-AmP-MCF afforded the highest rates. This may be explained by a facilitated mass transfer of the reagents into the MCF material through the wider pore windows ( $13 \mathrm{~nm}$ for AmP-MCF vs. $1.6 \mathrm{~nm}$ for MIL101- $\mathrm{NH}_{2}(\mathrm{Cr})$ ). It is noteworthy that allylic alcohol 4 a could not be observed at any moment in any of the experiments described until this point. To rule out the intermediacy of $4 \mathrm{a}$ in the formation of $\mathbf{2 a}$ (Pathway D) we attempted the isomerization of the allylic alcohol (4a). However, none of the three catalysts afforded aldehyde $\mathbf{2}$ a. Furthermore, it was demonstrated that $\mathbf{4} \mathbf{a}$ is rapidly reduced to $\mathbf{3} \mathbf{a}$ (Pathway $C^{\prime}$ ) under the reaction conditions (i.e., $1 \mathrm{~mol} \%$ of $\mathrm{Pd}^{0}-\mathrm{MIL}-101-\mathrm{NH}_{2}(\mathrm{Cr})$ under $1 \mathrm{~atm} \mathrm{H}_{2}$ reduces cinnamyl alcohol (4a) into 3-phenylpropan1-ol ( 3 a) with a TOF three times higher than in the case of cinnamaldehyde). In further control experiments, the attempted hydrogenation of $2 \mathrm{a}$ (stirred overnight under $1 \mathrm{~atm} \mathrm{H}_{2}$ ) in the presence either $\mathrm{Pd}^{0}-\mathrm{AmP}-\mathrm{MCF}$ or $\mathrm{Pd}^{0}-\mathrm{MIL}-101-\mathrm{NH}_{2}(\mathrm{Cr})$ did not produce compound $3 \mathrm{a}$. The absence of $\mathbf{3} \mathrm{a}$ in these experiments indicates that over-reduction via Pathway $C$ does not occur under the present conditions, and that $3 \mathrm{a}$ is only formed from intermediate allylic alcohol $4 \mathrm{a}$, which quickly reduces to form $3 \mathrm{a}$ in the reaction mixture (Pathways $B+C^{\prime}$ ).

We also considered that the readily oxidizable cinnamaldehyde ( 1 a) could be contaminated with trace amounts of cinnamic acid. This species could then activate the carbonyl moiety towards hydrogenation (via hydrogen bonding), which would favor formation of the over-reduced product $3 \mathrm{a}$ via Pathways $\mathrm{B}+\mathrm{C}^{\prime}$. However, $\mathbf{3}$ a also was observed in similar amounts when freshly distilled cinnamaldehyde was used.

\begin{tabular}{|c|c|c|c|c|c|c|c|}
\hline \multirow[b]{2}{*}{ Entry } & \multirow{2}{*}{ Catalyst } & \multicolumn{2}{|c|}{$\begin{array}{c}\text { Pd cat. ( } 1 \mathrm{~mol} \%) \\
1 \mathrm{~atm} \mathrm{H}_{2} \\
\underset{\text { Solvent }(0.4 \mathrm{M})}{20^{\circ} \mathrm{C} \text {, Time }}\end{array}$} & $2 a$ & \multirow[b]{2}{*}{$\begin{array}{l}\text { Conv. } \\
{[\%]^{[b]}}\end{array}$} & \multicolumn{2}{|c|}{$3 a$} \\
\hline & & & Solvent & $\begin{array}{l}t \\
{[\mathrm{~min}]}\end{array}$ & & $2 a / 3 a^{[b]}$ & $\begin{array}{l}2 \mathrm{a} \\
{[\%]^{[b]}}\end{array}$ \\
\hline 1 & \multirow{5}{*}{\multicolumn{2}{|c|}{$\mathrm{Pd}^{0}-\mathrm{MIL}-101-\mathrm{NH}_{2}(\mathrm{Cr})$}} & acetone & 30 & 55 & $85: 15$ & 47 \\
\hline 2 & & & acetone & 60 & 86 & $87: 13$ & 75 \\
\hline 3 & & & acetone & 90 & $>99$ & $89: 11$ & 89 \\
\hline 4 & & & EtOAc & 90 & $>99$ & $90: 10$ & 90 \\
\hline 5 & & & toluene & 90 & $>99$ & $89: 11$ & 89 \\
\hline 6 & \multirow{4}{*}{\multicolumn{2}{|c|}{$P d^{0}-A m P-M C F$}} & acetone & 30 & 88 & $86: 14$ & 76 \\
\hline 7 & & & EtOAc & 30 & 96 & $94: 6$ & 90 \\
\hline 8 & & & EtOAc & 60 & $>99$ & $92: 8$ & 92 \\
\hline 9 & & & toluene & 30 & 66 & $87: 13$ & 57 \\
\hline 10 & \multirow{4}{*}{\multicolumn{2}{|c|}{$\mathrm{Pd} / \mathrm{C}^{[\mathrm{c}]}$}} & acetone & 30 & 40 & $55: 45$ & 22 \\
\hline 11 & & & acetone & 60 & 68 & $55: 45$ & 37 \\
\hline 12 & & & EtOAc & 30 & 50 & $73: 27$ & 37 \\
\hline 13 & & & toluene & 30 & 36 & $50: 50$ & 18 \\
\hline
\end{tabular}

[a] Unless otherwise noted, reactions were performed on a $0.8 \mathrm{mmol}$ scale under $1 \mathrm{~atm}$ of $\mathrm{H}_{2}$ at $20^{\circ} \mathrm{C}$. [b] Determined by ${ }^{1} \mathrm{H}$ NMR spectroscopy from the crude reaction mixture. [c] $10 \mathrm{wt} \% \mathrm{Pd}$. 
Therefore, the effect of a base additive such as $\mathrm{K}_{2} \mathrm{CO}_{3}$, which could neutralize acidic species in-situ, was investigated for the three different catalysts (Table 2). When Pd ${ }^{0}-\mathrm{MIL}-101-\mathrm{NH}_{2}(\mathrm{Cr}$ ) was used, the addition of $\mathrm{K}_{2} \mathrm{CO}_{3}$ ( 0.1 equiv) was detrimental for the selectivity (Table 2 , entries $1-3$ vs. Table 1, entries 3-5). However, these results are consistent with our ${ }^{[13]}$ and others ${ }^{[14]}$ recent investigations on the stability of the MIL-101(Cr) framework in basic media. The presence of $\mathrm{K}_{2} \mathrm{CO}_{3}$ leads to a degradation of the porous framework, which can no longer prevent the agglomeration of $\mathrm{Pd}$ nanoparticles. Large $\mathrm{Pd}$ aggregates can then be responsible for the decreased selectivity as discussed above. ${ }^{[11]}$ Conversely, for the $\mathrm{Pd}^{0}-\mathrm{AmP}-\mathrm{MCF}$ catalyst, which is not base-sensitive, the presence of $\mathrm{K}_{2} \mathrm{CO}_{3}$ had a negligible effect on the selectivity in EtOAc (Table 2, entry 4 vs. Table 1, entry 7). However, in acetone the selectivity increased to $>99 \%$ in the presence of $\mathrm{K}_{2} \mathrm{CO}_{3}$, and quantitative formation of $2 \mathrm{a}$ was observed within $60 \mathrm{~min}$ (Table 2, entries 5 and 6). Compared to the two nanocatalysts, $\mathrm{Pd} / \mathrm{C}$ still exhibited lower conversions (29-52\%) and selectivities (57-82\%), even in the presence of base (Table 2, entries 7-10). Other solvents and additives were investigated under similar conditions but this did not lead to any further improvements of the reaction (see the Supporting Information for further details).

Since the addition of base did not improve the selectivity in the reactions catalyzed by $\mathrm{Pd}^{0}-\mathrm{MIL}-101-\mathrm{NH}_{2}(\mathrm{Cr})$, further optimization of this catalytic system was carried out by investigating

\begin{tabular}{|lllllll}
\hline Table 2. Influence of base addition and dilution on the Pd-catalyzed hy- \\
drogenation reactions. ${ }^{[a]}$
\end{tabular}

[a] Unless otherwise noted, reactions were performed on a $0.8 \mathrm{mmol}$ scale under $1 \mathrm{~atm}$ of $\mathrm{H}_{2}$ at room temperature. [b] Determined by ${ }^{1} \mathrm{H}$ NMR spectroscopy of the crude reaction mixture. [c] Traces of 4 a were observed when the reaction was allowed to stir, overnight. [d] Reaction diluted from 0.4 to $0.2 \mathrm{M}$ and no base additive used. [e] $10 \mathrm{wt} \% \mathrm{Pd}$. the effect of the substrate concentration. Gratifyingly, we found that lowering the substrate concentration from 0.4 to $0.2 \mathrm{M}$ without the addition of base, improved the selectivity significantly (Table 2, entries 11-15). This surprising effect could be attributed to the presence of $\mathrm{Cr}$ Lewis acidic sites in the structure of the MOF, which are prone to be exposed on the surface of the crystals and coordinate to the carbonylic oxygen atoms, activating them towards the undesired reduction of the $\mathrm{C}=\mathrm{O}$. Interestingly, in all experiments catalyzed by Pd@MOF, the by-product $(3 \mathrm{a})$ is formed in the earliest stages of the reaction. By diluting the reaction mixture from 0.4 to $0.2 \mathrm{M}$, the concentration of exposed acidic $\mathrm{Cr}$ sites is reduced, decreasing their chances to activate $\mathrm{C}=\mathrm{O}$ bonds towards undesired reduction. On the other hand, the dilution of the reaction medium could simply render the whole catalyst less active, thus improving the overall selectivity. Changing the solvent still did not drastically affect the outcome of the reactions; quantitative conversions and similarly high selectivities (94-95\%) were recorded in each of the three solvents that were examined after 90 min of reaction time. Further diluting the reaction had no beneficial effect and running the reaction under neat conditions afforded a very low conversion with a selectivity of $92 \%$ (Table 2, entry 16). For comparison, the use of $\mathrm{Pd} / \mathrm{C}$ under similar conditions $(0.2 \mathrm{M}$, no base) resulted in lower conversion $(69 \%)$ and a very poor selectivity (60\%) after 90 min (Table 2, entries 17-19). For the reactions with $\mathrm{Pd}^{0}-\mathrm{AmP}-\mathrm{MCF}$, only negligible improvements in selectivity were observed when the reaction was performed without base and with a substrate concentration of $0.2 \mathrm{M}$ compared to the reaction with $0.4 \mathrm{M}$.

The screening experiments described clearly demonstrate that $\mathrm{Pd}^{0}-\mathrm{MIL}-101-\mathrm{NH}_{2}(\mathrm{Cr})$ and $\mathrm{Pd}^{0}$-AmP-MCF display a significantly higher selectivity for the reduction of the olefinic bond in $\alpha, \beta$-unsaturated carbonyl compounds compared to commercially available $\mathrm{Pd} / \mathrm{C}$. Even more, the remarkable reactivity of the two nanocatalysts enables them to operate under very mild conditions, avoiding over-reduction of the reaction product. Under the optimized conditions, the well-controlled size and shape of the encapsulated nanoparticles (ca. 2-3 nm; see Supporting Information, Figure S1) in MIL-101- $\mathrm{NH}_{2}(\mathrm{Cr})$ and in AmP-MCF inhibits the undesired reduction of the $C=O$ bond (Pathway B, Figure 1), previously observed with larger nanoparticles. ${ }^{[11 \mathrm{~b}]}$ To the best of our knowledge, the results reported herein for the Pd@MCF and Pd@MOF catalysts are unsurpassed in terms of TOF and selectivity (see the Supporting Information for details) by any heterogeneous Pd catalysts in the selective hydrogenation of cinnamaldehyde under ambient conditions (room temperature and $1 \mathrm{~atm}$ of $\mathrm{H}_{2}$ ). A review of recent literature on the topic revealed that only catalysts operating under much harsher conditions (up to $70^{\circ} \mathrm{C}$ and up to $20 \mathrm{~atm} \mathrm{H}_{2}$ ) manage to return higher turnover frequencies and comparable selectivities.

Next, the catalytic efficiency of $\mathrm{Pd}^{0}-\mathrm{MIL}-101-\mathrm{NH}_{2}(\mathrm{Cr})$ and $\mathrm{Pd}^{0}-$ AmP-MCF was compared for the chemoselective hydrogenation of crotonaldehyde (1 b) and methacrolein (1 c), which are challenging substrates but highly interesting, since butanal ( $\mathbf{2}$ b) and isobutanal ( $\mathbf{2}$ c) are industrially important chemical intermediates. ${ }^{[15]}$ Although both catalysts had no difficulties in 


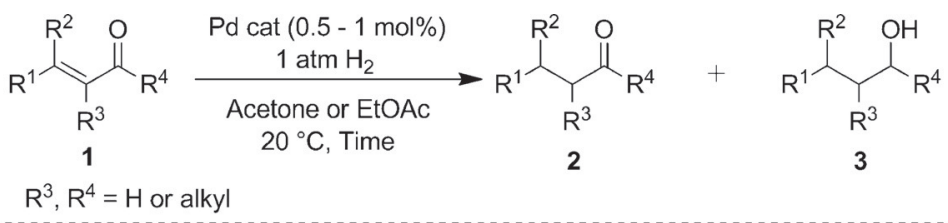

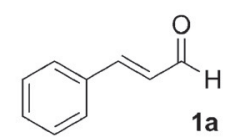

\section{Pd ${ }^{0}-\mathrm{MIL}-101-\mathrm{NH}_{2}$}

$1 \mathrm{~mol} \% \mathrm{Pd}, 90 \mathrm{~min}$

Conversion: $>99 \%$

Sel. (2a/3a): 95/5

\section{$\mathrm{Pd}^{0}$-AmP-MCF}

$1 \mathrm{~mol} \% \mathrm{Pd}, 60 \mathrm{~min}^{[\mathrm{a}]}$ Conversion: $>99 \%$ Sel. $(2 a / 3 a)$ : >99/1<smiles>C/C=C/C=O</smiles>

$\mathrm{Pd}^{0}$-MIL-101- $\mathrm{NH}_{2}$

$1 \mathrm{~mol} \% \mathrm{Pd}, 75 \mathrm{~min}$ Conversion: $>99 \%$ Sel. (2b/3b): $95 / 5$
$1 b$

\section{$\mathrm{Pd}^{0}$-AmP-MCF}

$0.5 \mathrm{~mol} \% \mathrm{Pd}, 15 \mathrm{~min}$ Conversion: $>99 \%$ Sel. $(2 b / 3 b):>99 / 1$<smiles>C=CC(=O)C=O</smiles>

\section{$\mathrm{Pd}^{0}$-MIL-101- $\mathrm{NH}_{2}$ \\ $\mathrm{Pd}^{0}$-AmP-MCF \\ $1 \mathrm{~mol} \% \mathrm{Pd}, 60 \mathrm{~min}$ \\ Conversion: $>99 \%$ \\ Sel. (2c/3c): $90 / 10$ \\ $0.5 \mathrm{~mol} \% \mathrm{Pd}, 15 \mathrm{~min}$ \\ Conversion: $>99 \%$ \\ Sel. $(2 c / 3 c)$ : $>99 / 1$}<smiles>CC(=O)/C=C/c1ccccc1</smiles>

\section{$\mathrm{Pd}^{0}$-MIL-101-NH}

$1 \mathrm{~mol} \% \mathrm{Pd}, 75 \mathrm{~min}$

Conversion: $>99 \%$

Sel. $(2 d / 3 d):>99 / 1$

\section{$\mathrm{Pd}^{0}$-AmP-MCF}

$1 \mathrm{~mol} \% \mathrm{Pd}, 30 \mathrm{~min}$

Conversion: $>99 \%$

Sel.(2d/3d): >99/1

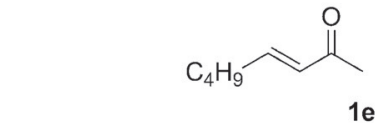

\section{Pd $^{0}$-MIL-101- $\mathrm{NH}_{2}$}

$1 \mathrm{~mol} \% \mathrm{Pd}, 45 \mathrm{~min}$

Conversion: $>99 \%$

Sel. $(2 e / 3 e)$ : $>99 / 1$
$\mathrm{Pd}^{0}$-AmP-MCF

$1 \mathrm{~mol} \% \mathrm{Pd}, 15 \mathrm{~min}$,

Conversion: $>99 \%$

Sel. $(2 e / 3 e)$ : $>99 / 1$<smiles>CC1=CCCC1=O</smiles>

$\mathrm{Pd}^{0}$-MIL-101-NH

$1 \mathrm{~mol} \% \mathrm{Pd}, 75 \mathrm{~min}$

Conversion: $>99 \%$

Sel. (2f/3f): 96/4
Pd $^{0}$-AmP-MCF
1 mol\% Pd, 10 min
Conversion: $>99 \%$
Sel. $(2 f / 3 f):>99 / 1$

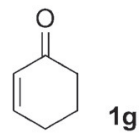

$1 \mathrm{~g}$

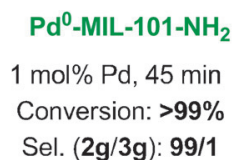

\section{$\mathrm{Pd}^{0}$-AmP-MCF}

$0.5 \mathrm{~mol} \% \mathrm{Pd}, 10 \mathrm{~min}$

Conversion: $>99 \%$

Sel. $(\mathbf{2 g} / 3 \mathrm{~g})$ : $>99 / 1$

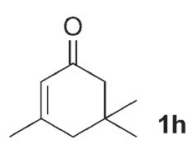

$\mathrm{Pd}^{0}-\mathrm{MIL}-101-\mathrm{NH}_{2}$

$\mathrm{Pd}^{0}$-AmP-MCF

$1 \mathrm{~mol} \% \mathrm{Pd}, 75 \mathrm{~min}$

Conversion: $>99 \%$

Sel. (2h/3h): $99 / 1$
$1 \mathrm{~mol} \% \mathrm{Pd}, 60 \mathrm{~min}$ Conversion: $>99 \%$ Sel. $(2 h / 3 h)$ : >99/1

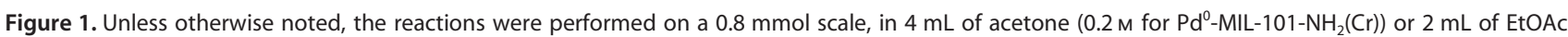
$\left(0.4 \mathrm{M}\right.$ for $\left.\mathrm{Pd}^{0}-\mathrm{AmP}-\mathrm{MCF}\right)$ at $20^{\circ} \mathrm{C}$ and under $\mathrm{H}_{2}$ atmosphere (balloon, $\left.1 \mathrm{~atm}\right)$, for the indicated time. The progress of the reaction was monitored by ${ }^{1} \mathrm{H}$ NMR analysis of the crude reaction mixture. [a] The reaction was run in acetone in the presence of 0.1 equiv of $\mathrm{K}_{2} \mathrm{CO}_{3}$.

providing full conversions, $\mathrm{Pd}^{0}$-AmP-MCF was found to be slightly faster while also affording excellent selectivity, even when using a loading of $\mathrm{Pd}$ as low as $0.5 \mathrm{~mol} \%$. On the other hand, the slightly lower selectivity of the Pd@MOF catalyst ( $95 \%$ and $90 \%$ for $\mathbf{2} \mathbf{b}$ and $\mathbf{2}$ c, respectively) can be again attributed to the presence of Lewis acidic $\mathrm{Cr}$ sites on the framework, which are even more easily accessed by the small molecules of substrates $\mathbf{1} \mathbf{b}$ and $\mathbf{1} \mathbf{c}$.

The selectivity was also excellent for linear $\alpha, \beta$-unsaturated ketones. Both aromatic (1 d) and aliphatic (1 e) substrates were efficiently hydrogenated with complete selectivity by both catalysts, the reaction being faster for $\mathrm{Pd}^{0}$-AmP-MCF. Cyclic substrates $(\mathbf{1} \mathbf{f}-\mathbf{1} \mathbf{h})$ were also well tolerated even when the double bond was substituted ( $\mathbf{1} \mathbf{f}$ and $\mathbf{1} \mathbf{h}$ ), and full conversions were achieved in a matter of minutes, displaying the versatility of these Pd nanocatalysts. Only trace amounts of alcohols $\mathbf{3} \mathbf{f}-\mathbf{3} \mathbf{h}$ were observed for $\mathrm{Pd}^{0}-\mathrm{MIL}-101-\mathrm{NH}_{2}(\mathrm{Cr})$ while $\mathrm{Pd}^{0}-\mathrm{AmP}-\mathrm{MCF}$ provided the desired products $\mathbf{2} \mathbf{f}-\mathbf{2} \mathbf{h}$ with complete selectivity. However, in the case of the cyclic enone $\mathbf{1} \mathbf{g}$ the formation of the over-reduced byproduct $\mathbf{3} \mathbf{g}$ could be observed on prolonged reaction times. Gratifyingly, all products $\mathbf{2} \mathbf{b}-\mathbf{2} \mathbf{h}$ were obtained in excellent yields and selectivities without the addition of base.

\section{Stability and leaching}

The initial recycling studies were conducted with the model substrate cinnamaldehyde $(1 \mathrm{a})$, in the presence $\mathrm{K}_{2} \mathrm{CO}_{3}$ and using $\mathrm{Pd}^{0}$-AmP-MCF as the catalyst. The reaction time was shortened to $30 \mathrm{~min}$ in order to clearly asses the catalyst efficiency for each cycle. During three consecutive cycles, a gradual decrease $(67,53$ and $43 \%)$ in the conversion towards the desired product 2 a was observed, although the selectivity was unchanged. Since the recycling of cinnamaldehyde was not optimal for $\mathrm{Pd}^{0}$-AmP-MCF, we did not evaluate the recyclability of $\mathrm{Pd}^{0}-\mathrm{MIL}-101-\mathrm{NH}_{2}(\mathrm{Cr})$ for this substrate. However, when ketone $1 \mathrm{~d}$ was subjected to recycling studies, both $\mathrm{Pd}^{0}$-MIL101- $\mathrm{NH}_{2}(\mathrm{Cr})$ and $\mathrm{Pd}^{0}$-AmP-MCF showed a very stable behavior with no differences in reactivity over five runs (Table 3 ). In each case, full conversion and excellent selectivity towards $\mathbf{2} \mathbf{d}$ were obtained after 75 min for $\mathrm{Pd}^{0}-\mathrm{MIL}-101-\mathrm{NH}_{2}(\mathrm{Cr})$ and after $30 \mathrm{~min}$ for $\mathrm{Pd}^{0}$-AmP-MCF. Over the five runs, the amount of leached 
Pd was kept at barely detectable levels by ICP-OES $(\leq 0.2 \mathrm{ppm})$ for both catalysts (Table 3 ). The analysis of HAADF-STEM and TEM images of $\mathrm{Pd}^{0}-\mathrm{MIL}-101-\mathrm{NH}_{2}(\mathrm{Cr})$ revealed that in general, most nanoparticles retain their original size and shape (see Supporting Information, Figures S1 and S2). In the fresh catalyst about $85 \%$ of the nanoparticles fit in a very narrow size distribution range between 1.5 and $2.5 \mathrm{~nm}$ and altogether more than $95 \%$ of the nanoparticles are smaller than the pore size limit of the MOF ( $34 \AA$ ). After five recycling runs, some redistribution of Pd is observed but still about $87 \%$ of the nanoparticles remain under the size limit imposed by the MOFs pores. The other $13 \%$ of $\mathrm{Pd}$ nanoparticles, which are larger in size, are located on the surface of the MOF crystallites. This can happen due to $\mathrm{Pd}$ migration or degradation of the MOF by mechanical factors. Still, maintaining most of the Pd species in a very narrow size range shows that the porous support is actively protecting the catalyst against the natural Ostwald ripening and thus prolongs its lifetime. The XRPD patterns of fresh and recycled $\mathrm{Pd}^{0}-\mathrm{MIL}-101-\mathrm{NH}_{2}(\mathrm{Cr})$ after five runs were identical with no distinguishable loss in crystallinity (Supporting Information, Figure S3). However, small amounts of $\mathrm{Cr}$ were detected in the third and fifth run (Table 3), most likely caused by the mechanical stress to which the MOF crystals are subjected during reaction cycles under vigorous stirring.

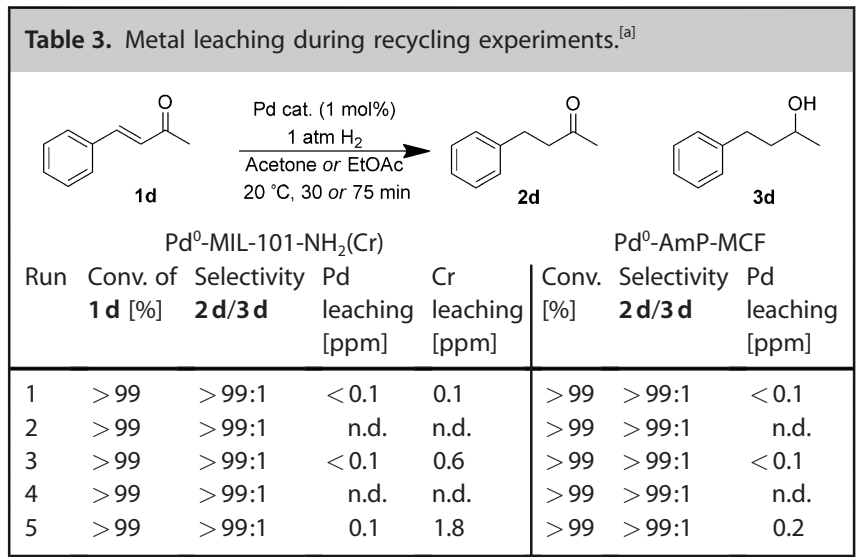

[a] Conditions for reactions with $\mathrm{Pd}^{0}-\mathrm{MIL}-101-\mathrm{NH}_{2}(\mathrm{Cr})$ : The reactions were performed on a $0.8 \mathrm{mmol}$ scale, in $4 \mathrm{~mL}$ of acetone at $20^{\circ} \mathrm{C}$ and under $\mathrm{H}_{2}$ atmosphere (balloon, $1 \mathrm{~atm}$ ), for $75 \mathrm{~min}$. Conditions for reactions with $\mathrm{Pd}^{0}$-AmP-MCF: The reactions were performed on a $0.8 \mathrm{mmol}$ scale, in $2 \mathrm{~mL}$ of EtOAc at $20^{\circ} \mathrm{C}$ and under $\mathrm{H}_{2}$ atmosphere (balloon, 1 atm), for $30 \mathrm{~min}$. It was shown in the first run that the reaction of $\mathrm{Pd}^{0}$-AmP-MCF required at least $10 \mathrm{~min}$ for full conversion.

When the $\mathrm{Pd}^{0}$-AmP-MCF was subjected to a similar HAADFSTEM and TEM analysis, a slightly wider size distribution was observed in the fresh catalyst with only $40 \%$ of the nanoparticles in the $1.5-2.5 \mathrm{~nm}$ range and $50 \%$ in the $2.5-3.5 \mathrm{~nm}$ range, while the remaining $10 \%$ of the nanoparticles were larger than $4 \mathrm{~nm}$ (see Supporting Information, Figures S4 and S5). This is not surprising considering the wider pore apertures of the MCF materials. However, we were delighted to find that after five recycling runs, the level of $\mathrm{Pd}$ agglomeration is barely detectable and most nanoparticles retain their size with ca. $90 \%$ of them remaining under $3.5 \mathrm{~nm}$. This is in accordance with the previous results where $\mathrm{Pd}^{0}$-AmP-MCF had been used for hydrogenation of nitroarenes and no agglomeration was detected. ${ }^{[16]}$

\section{Conclusions}

The two composite materials, $\mathrm{Pd}^{0}-\mathrm{MIL}-101-\mathrm{NH}_{2}(\mathrm{Cr})$ and $\mathrm{Pd}^{0}-$ AmP-MCF have shown excellent activity in the selective hydrogenation of the $C=C$ bond in various $\alpha, \beta$-unsaturated carbonyl compounds, with all substrates reaching a full conversion within 90 min under only $1 \mathrm{~atm}$ of $\mathrm{H}_{2}$. Under the optimized reaction conditions, both $\mathrm{Pd}^{0}-\mathrm{AmP}-\mathrm{MCF}$ and $\mathrm{Pd}^{0}-\mathrm{MIL}-101-\mathrm{NH}_{2}(\mathrm{Cr})$ are able to prevent agglomeration of $\mathrm{Pd}$ nanoparticles, prolonging their lifetime and maintaining their size and facet dependent properties. This property provides both catalysts with a remarkable control of the chemoselectivity of the reaction, which is not achieved with commercially available $\mathrm{Pd} / \mathrm{C}$. Over multiple recycling runs the contamination of leached metallic species was kept at a minimum level. However, in this comparative study, $\mathrm{Pd}^{0}$-AmP-MCF proved to be slightly more effective than $\mathrm{Pd}^{0}-\mathrm{MIL}-101-\mathrm{NH}_{2}(\mathrm{Cr})$, and its excellent performance at low catalyst loadings makes it highly attractive for hydrogenations in industrial settings.

\section{Experimental Section}

\section{General information}

Reagents and solvents were used as obtained from commercial suppliers without further purification, except cinnamaldehyde, which was distilled under reduced pressure before use. $\mathrm{Pd}^{0}$-MIL$101-\mathrm{NH}_{2}(\mathrm{Cr})(8.40 \mathrm{wt} \%)$ and $\mathrm{Pd}^{0}$-AmP-MCF $(7.90 \mathrm{wt} \%)$ were synthesized according to previously reported procedures, described in the Supporting Information.

${ }^{1} \mathrm{H}$ NMR spectra were recorded at $400 \mathrm{MHz}$ on a Bruker Advance spectrometer. ${ }^{1} \mathrm{H}$ chemical shifts $(\delta)$ are reported in ppm from tetramethylsilane with the solvent resonance as the internal standard $\left(\mathrm{CDCl}_{3}: \delta_{\mathrm{H}}=7.26 \mathrm{ppm}\right)$. Elemental analysis: determinations of $\mathrm{Pd}$ and $\mathrm{Cr}$ were performed by inductively coupled plasma optical emission spectrometry (ICP-OES) with a Varian Vista MPX instrument. Medac Ltd. in the UK carried out the elemental analysis. Xray powder siffraction (XRPD) data were collected on a PANalytical $X$ 'Pert PRO diffractometer in reflectance Bragg-Brentano geometry equipped with a pixel detector and using $\mathrm{Cu}_{\mathrm{k} \alpha 1}$ radiation. MIL-101 samples were suspended in $\mathrm{EtOH}$, dispersed on zero-background Si plates and dried at room temperature. The morphology of "samples" was examined in a JEOL-2100F transmission electron microscope operated at $200 \mathrm{kV}$ and equipped with a Schottky-type field emission gun. The crushed samples were dispersed in ethanol and then onto a TEM Cu grid with holey carbon supporting films. Bright-field and high-resolution TEM (HRTEM) images were recorded by a CCD camera (Gatan Ultrascan 1000). High-angle annular dark-field scanning transmission electron microscopy (HAADFSTEM), also known as Z-contrast, images for determining the size and distribution of $\mathrm{Pd}$ nanoparticles were acquired using a JEOL ADF detector. The probe size and camera length used are $0.20 \mathrm{~nm}$ and $8 \mathrm{~cm}$, respectively. 


\section{General procedure for the $\mathrm{Pd}^{0}$-catalyzed hydrogenation of enals and enones}

The corresponding enal or enone $(0.8 \mathrm{mmol})$ and $\mathrm{Pd}^{0}-\mathrm{MCF} / \mathrm{MOF}$ (4-8.0 $\mu \mathrm{mol} \mathrm{Pd}, 0.50-1 \mathrm{~mol} \%)$ were suspended in the chosen solvent (MCF: EtOAc, $2 \mathrm{~mL}$ or MOF: acetone, $4 \mathrm{~mL}$ ) in a screw-capped Radley tube. The reaction vessel was then evacuated and filled with hydrogen gas from a balloon in three repeating cycles. The reaction was allowed to stir at room temperature for the indicated time with the $\mathrm{H}_{2}$ balloon attached, after which the reaction was stopped. Aliquots were taken from the reaction mixture, filtered through Celite, eluted with $\mathrm{CDCl}_{3}(1 \mathrm{~mL})$, and analyzed by ${ }^{1} \mathrm{H}$ NMR spectroscopy to determine the conversion and selectivity. See the Supporting Information for more details.

\section{Acknowledgements}

The Swedish Research Council (VR), the Swedish Governmental Agency for Innovation Systems (VINNOVA), the Berzelii Center EXSELENT, and the Knut and Alice Wallenberg Foundation are gratefully acknowledged for project grants. The Knut and Alice Wallenberg Foundation is also acknowledged for an equipment grant for the electron microscopy facilities at Stockholm University. The help of Dr. Fabian Carson for measuring XRPD patterns at Stockholm University is gratefully acknowledged.

Keywords: heterogeneous catalysis - mesocellular foam metal-organic framework · palladium nanoparticles $\cdot$ selective hydrogenation

[1] G. Dormán, L. Kocsis, R. Jones, F. Darvas, J. Chem. Health Saf. 2013, 20, 3-8.

[2] a) S. Fujiwara, N. Takanashi, R. Nishiyabu, Y. Kubo, Green Chem. 2014, 16, $3230-3236$; b) S. Ganji, S. Mutyala, C. K. P. Neeli, K. S. R. Rao, D. R. Burri, RSC Adv. 2013, 3, 11533-11538; c) Z. Wei, Y. Gong, T. Xiong, P. Zhang, H. Li, Y. Wang, Catal. Sci. Technol. 2015, 5, 397-404; d) M. S. Ide, B. Hao, M Neurock, R. J. Davis, ACS Catal. 2012, 2, 671-683; e) J.-H. Yang, D. Ma, RSC Adv. 2013, 3, 10131-10134; f) L. Chen, H. Chen, Y. Li, Chem. Commun. 2014, 50, 14752.

[3] H. Furukawa, K. E. Cordova, M. O'Keeffe, O. M. Yaghi, Science 2013, 341, 1230444.

[4] For recent developments of catalytic processes with MOFs, see: a) A. H Chughtai, N. Ahmad, H. A. Younus, A. Laypkov, F. Verpoort, Chem. Soc. Rev. 2015, 44, 6804-6849; for loading of Pd nanoparticles on functionalized MOF: b) V. Pascanu, Q. Yao, A. Bermejo Gómez, M. Gustafsson, Y. Yun, W. Wan, L. Samain, X. Zou, B. Martín-Matute, Chem. Eur. J. 2013, 19,
17483-17493; c) V. Pascanu, P. R. Hansen, A. Bermejo Gómez, C. Ayats, A. E. Platero-Prats, M. J. Johansson, M. À. Pericàs, B. Martín-Matute, ChemSusChem 2015, 8, 123-130; d) V. Pascanu, F. Carson, M. V. Solano, J. Su, X. Zou, M. J. Johansson, B. Martín-Matute, Chem. Eur. J. 2016, 22, 3729-3737.

[5] For recent developments of catalytic processes with $\mathrm{Pd}^{0}$-AmP-MCF, see: a) E. Bratt, O. Verho, M. J. Johansson, J.-E. Bäckvall, J. Org. Chem. 2014 79, 3946; b) K. Engström, E. V. Johnston, O. Verho, K. P. J. Gustafson, M. Shakeri, C.-W. Tai, J.-E. Bäckvall, Angew. Chem. Int. Ed. 2013, 52, $14006-$ 14010; Angew. Chem. 2013, 125, 14256-14260; c) J. Malmgren, A. Nagendiran, C.-W. Tai, J.-E. Bäckvall, B. Olofsson, Chem. Eur. J. 2014, 20, 13531 -13535.d) O. Verho, A. Nagendiran, E. V. Johnston, C.-W. Tai, J.-E. Bäckvall, ChemCatChem 2013, 5, 612-618.

[6] For a comprehensive review on MOF supported nanoparticles, see: A. Dhakshinamoorthy, H. Garcia, Chem. Soc. Rev. 2012, 41, 5262-5284.

[7] For a comprehensive review on MCF, see: A. Taguchi, F. Schüth, Microporous Mesoporous Mater. 2005, 77, 1-45.

[8] a) G. Collins, M. Schmidt, C. O'Dwyer, J. D. Holmes, G. P. McGlacken, Angew. Chem. Int. Ed. 2014, 53, 4142-4145; Angew. Chem. 2014, 126, 4226-4229; b) J. Zhang, C. Feng, Y. Deng, L. Liu, Y. Wu, B. Shen, C. Zhong, W. Hu, Chem. Mater. 2014, 26, 1213-1218.

[9] For MCF synthesis, see: a) Y. Han, S. S. Lee, J. Y. Ying, Chem. Mater. 2006, 18, 643-649; b) M. Shakeri, K. Kawakami, Microporous Mesoporous Mater. 2009, 118, 115-120; for loading of Pd nanoparticles and applications see: c) E. V. Johnston, O. Verho, M. D. Kärkäs, M. Shakeri, C.-W. Tai, P. Palmgren, K. Eriksson, S. Oscarsson, J.-E. Bäckvall, Chem. Eur. J. 2012, $18,12202-12206$.

[10] For MOF synthesis see: a) G. Férey, C. Mellot-Draznieks, C. Serre, F. Millange, J. Dutour, S. Surblé, I. Margiolaki, Science 2005, 309, 2040-2042; b) For $\mathrm{NH}_{2}$ post-synthetic functionalization see: S. Bernt, V. Guillerm, C. Serre, N. Stock, Chem. Commun. 2011, 47, 2838-2840.

[11] a) C. Vriamont, T. Haynes, E. McCague-Murphy, F. Pennetreau, O. Riant, S. Hermans, J. Catal. 2015, 329, 389-400; b) L. J. Durndell, C. M. A. Parlett, N. S. Hondow, M. A. Isaacs, K. Wilson, A. F. Lee, Sci. Rep. 2015, 5, 9425.

[12] It should be noted that the high selectivity was observed with $\mathrm{Pd}^{0}$ AmP-MCF with a Pd loading of 7.90 wt \%.

[13] F. Carson, V. Pascanu, A. Bermejo Gómez, Y. Zhang, A. E. Platero-Prats, X. Zou, B. Martín-Matute, Chem. Eur. J. 2015, 21, 10896-10902.

[14] J. Gascon, A. Corma, F. Kapteijn, F. X. Llabrés i Xamena, ACS Catal. 2014, 4, 361-378.

[15] a) V. Babu, A. Thapliyal, G. K. Patel, Biofuel Production, Wiley, New York, 2013; b) E. R. Riegel, J. A. Kent, Kent and Riegel's Handbook of Industrial Chemistry and Biotechnology, Springer, New York, 2007; c) M. A. Benvenuto, Industrial Chemistry: for Advanced Students, de Gruyter, Berlin, 2015; d) S. Lee, Methane and its Derivatives, Taylor \& Francis, 1996.

[16] O. Verho, K. P. J. Gustafson, A. Nagendiran, C.-w. Tai, J.-E. Bäckvall, ChemCatChem 2014, 6, 3153-3159.

Received: February 24, 2016

Published online on April 25, 2016 